\title{
Research on Cutting Force and Cutting Vibration in Milling of PE WPC
}

\author{
Shi Wenyong ${ }^{1,2}$, Ma Yan ${ }^{1}$ and Yang Chunmei ${ }^{1}$ \\ ${ }^{1}$ Forest Woodworking Machinery Research and Development Center, Northeast \\ Forestry University, Harbin 150040, P R China \\ ${ }^{2}$ Division of Graduate, Harbin University of Science and Technology, Harbin \\ 150080, P R China \\ E-mail: shiwenyong@hrbust.edu.cn
}

\begin{abstract}
This paper presents the impact of the change of cutting parameters on cutting force and cutting vibration by the milling experiment of PE WPC. In the text, $60 \%$ wod flour content and $70 \%$ wood flour content WPC are compared in up milling and down milling. The result shows that cutting force shows a progressive increasing trend as the feed speed increasing. The cutting force in up milling is totally smallen than in down milling with the change of cutting speed. Cutting force shows an ncreasing trend with the cutting width increasing. The impact of feed speed on cutting vibration is more obvious. The cutting vibration of $60 \%$ wood flour content is more sasceptible than $70 \%$ wood flour content. In the cutting speed experiment, the cutting vibration in up milling is obviously bigger than in down milling. The cutting vibration of $60 \%$ and $70 \%$ wood flour content is almost the same in down milling. However, it is ppposite in milling. The cutting vibration shows a progressive increasing trend in down milling and steady in up milling as the cutting width increases.
\end{abstract}

Keywords: PE WPC; milling; cutting (orce; cutting vibration

\section{Introduction}

PE WPC is widely used in many kinds of industries, such as building materials, auto industry, packing and shipping of goods, warehousing, decoration materials, daily life tools and so on [1]. Cutting force and cutting vibration are two important physicals of cutting process [2-3]. They have close relationships with surface quality and power consumption. It is an mportant meaning for the milling of PE WPC [4-5].

In the cutting force aspect, the main factors are cutlery and cutting parameters. Engin [6] et al. did the MDF milling experiment. They tested the cutting component of X-axis and $\mathrm{Y}$-axis no the milling process. They also set up formulas of the two components with deed speed milling thickness and cutlery angle. Liu [7] designed the multiple regression analysis experiment. Spindle speed, feed speed and cutlery clearance angle are chosen as the factors. She researched WPC cutting performances such as cutting force, cutting temperature, Surface roughness and so on. Set up mathematical model of each cutting performance through the variation of each cutting performance. Through the experiment, Zhang [8] found that main cutting force and normal cutting force all decrease as the serrated rake angle increases and increase as the cutting thickness increases. Cutting speed has little impact on it. Zhang [9] then researched the impact of wood cutting direction on cutting force. The result shows that wood main cutting force has an anisotropy in different cutting directions. The main tend is the main cutting force is biggest in end direction and smallest in lateral. In the cutting vibration aspect, wood vibration cutting is pulse cutting. During the cutting process, cutlery leaves and contacts wood periodically. The size and direction of the speed are change constantly. Hessainia [10] studied the wood cutting 
vibration initially through the experiment. Eyma [11] studied the impact of cutting parameters on wood cutting vibration during the milling.

In summary, the research of PE WPC milling is relatively less. Thus, in this paper, we research the impact of cutting parameters on cutting force and cutting vibration to provide technical support for efficient and high-quality process.

\section{Experiment Settings}

\subsection{Experiment Materials and Equipment}

The experiment uses the PE WPC which is developed and made in State Key Laboratory for Materials of Northeast Forestry University. It is made up with PE, wood flour, coupling agent, lubricants and so on. The specific parameters are shown in Table 1.

Table 1. PE WPC Mechanical Properties

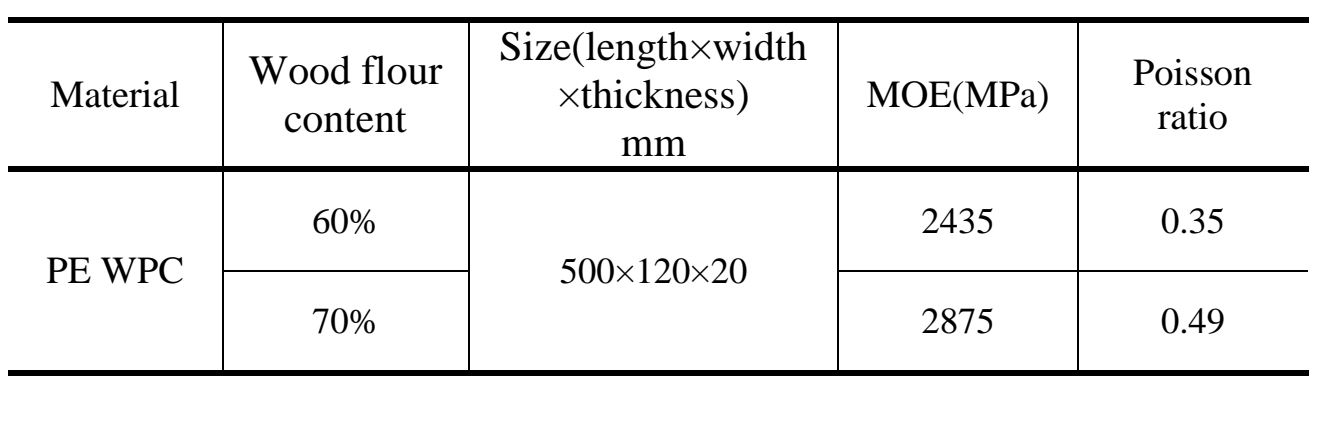

Experiment uses CNC milling, experimental equpment is shown in Figure 1. The machine tool is MIKRON UCP 710. Cutter is indexable insert cutter made by Leitz. The diameter of shank cutter is 30mmand model is WL101-2-040854. The blade model is HW-05-005161. The testing equipment used in the experiment are dynamometer, whose model is Kistler 9257B, and acceleration ransducer, whose model is Kistler 353A02.

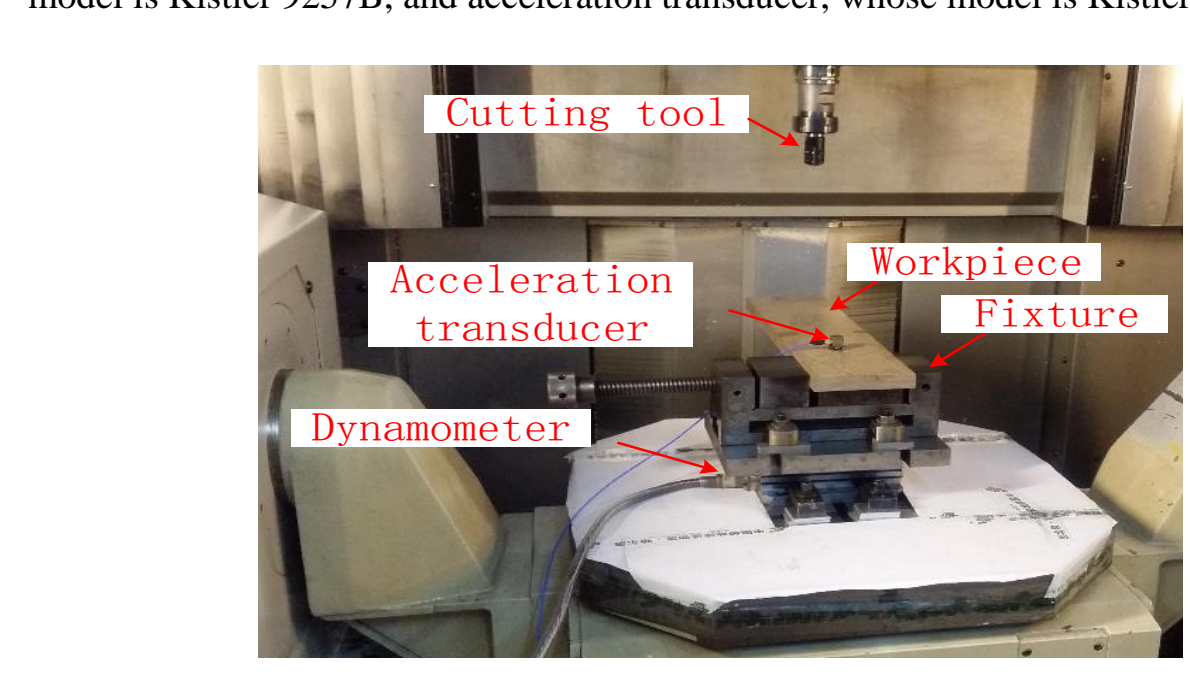

Figure 1. Experimental Equipment

\subsection{Experimental Methods}

Down milling and up milling are compared in the experiment. The test researches the impact of feed speed, cutting speed and cutting width on cutting force and cutting vibration (Concerning the material is sheet, cutting depth is without consideration). Table 2 shows the milling parameters of PE WPC. It concludes single factor experiment of feed speed, cutting speed and cutting width. 
Table 2. PE WPC Experiment Parameters

\begin{tabular}{c|c|c|c|c}
\hline Group & $\begin{array}{c}\text { Feed speed } \\
\mathrm{f}(\mathrm{m} / \mathrm{min})\end{array}$ & $\begin{array}{c}\text { Cutting speed } \\
\mathrm{v}(\mathrm{m} / \mathrm{min})\end{array}$ & $\begin{array}{c}\text { Cutting } \\
\text { width } \\
\mathrm{a}_{\mathrm{e}}(\mathrm{mm})\end{array}$ & $\begin{array}{c}\text { Cutting } \\
\text { depth } \\
\mathrm{a}_{\mathrm{p}}(\mathrm{mm})\end{array}$ \\
\hline 1 & $\begin{array}{c}2,4,6,8,10 \\
12,14\end{array}$ & 800 & 1 & 20 \\
\hline 2 & 6 & $400,600,800,1000,1200,1400,1600,1800$ & 1 & 20 \\
\hline 3 & 6 & 800 & $1,2,3,4,5,6$ & 20 \\
\hline
\end{tabular}

\section{Cutting Force Testing Result and Discussion}

\subsection{Impact of Feed Speed on Cutting Force}

Figure 2 shows the impact of feed speed on cutting force of WPC whose wood flour content is $60 \%$ and $70 \%$ in $\mathrm{XYZ}$ directions during down and up milling. From the figure we can see that when the content is $60 \%$ in down milling, the force of $\mathrm{X}$-axis increases from $13.9 \mathrm{~N}$ to $23.5 \mathrm{~N}$ as the feed speed increases. When $\mathrm{f}$ is $2-8 \mathrm{~m} / \mathrm{min}$, the force of $\mathrm{Z}$-axis is very steady and small $(5.5-6.3 \mathrm{~N})$. When $\mathrm{f}$ is $10-142-8 \mathrm{~m} / \mathrm{min}$, the force of Z-axis increases gradually. The cutting force of $\mathrm{Y}$-axis is biggest and almost linearly increases around $26-52.8 \mathrm{~N}$. And the increasing trend is biggen than $X$-axis and Zaxis. The cutting force of up milling is obviously bigger than down milling. Cutting force increases as the feed speed increases. The force of $\mathrm{Y}$-axis is biggest then is $\mathrm{X}$ and $\mathrm{Z}$-axis. The change tend of $\mathrm{X}$-axis cutting force, is similar with down milling, showing a slowly increasing trend (23.6-53.5N). Z-axis cutting force (6.9-36.2N) of each feed speed is smaller than X-axis and the curve is parallel with $\mathrm{X}$-axis $\mathrm{K}$ axis force $1 \mathrm{~s}$ larger and shows an obvious fluctuation.

For the impact of WPC whose Content is $70 \%$ in three directions, X-axis force is steady in Down milling and shows slight fluctuations in $7 \mathrm{~N}(23.3-30.3 \mathrm{~N})$. Z-axis force is very small. When $\mathrm{f}$ is $2-6 \mathrm{~m} / \mathrm{min}$, Z-axis forcedecreases from $10.9 \mathrm{~N}$ to $7.7 \mathrm{~N}$. When $\mathrm{f}$ is over $8 \mathrm{~m} / \mathrm{min}$, the force is around $6.7 \mathrm{~N}$. Y-axis force increases linearly from $36.3 \mathrm{~N}-62.6 \mathrm{~N}$. Xaxis force waves between $43.3 \mathrm{~N}$ and $74.3 \mathrm{~N}$. When $\mathrm{f}$ is $2-12 \mathrm{~m} / \mathrm{min}, \mathrm{Z}$-axis force waves slightly between $179 \mathrm{~N}$ and $33.2 \mathrm{~N}$. When $\mathrm{f}$ is $14 \mathrm{~m} / \mathrm{min}, \mathrm{Z}$-axis force suddenly increases to 109.2N. The impact is larger. The stability of $\mathrm{Y}$-axis force is bad and the cutting force waves obviøusiy

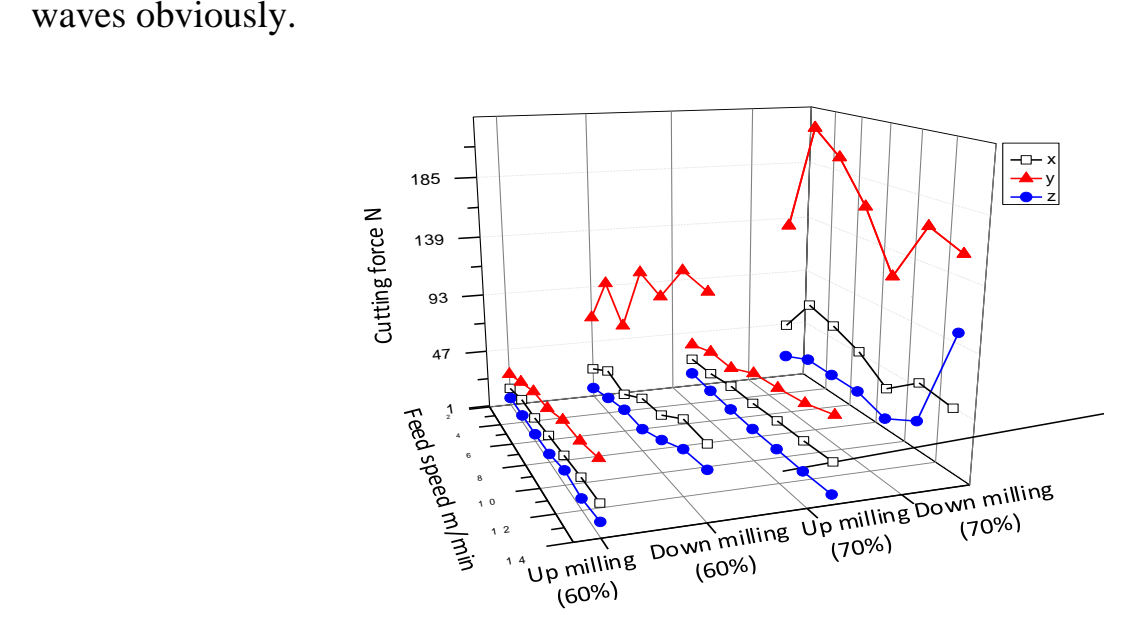

Figure 2. Impact of Feed Speed on Cutting Force

\subsection{Impact of Cutting Speed on Cutting Force}

Figure 3 shows the impact of cutting speed on cutting force of WPC whose wood flour content is $60 \%$ and $70 \%$ in XYZ directions during down and up milling. From the figure 
we can see that when the content is $60 \%$ in down milling, the force of $\mathrm{X}$-axis decreases from $24.8 \mathrm{~N}$ to $6.5 \mathrm{~N}$ as the cutting speed increases but the total change range is small. Zaxis force is generally between $15 \mathrm{~N}$ and $3 \mathrm{~N}$, which shows a decreasing tend. But when $\mathrm{v}$ is $1200 \mathrm{~m} / \mathrm{min}, \mathrm{Z}$-axis force suddenly increases to $21.3 \mathrm{~N}$. Y -axis force gradually decreases from $73.6 \mathrm{~N}$ to $18.3 \mathrm{~N}$. When $\mathrm{v}$ is $1200 \mathrm{~m} / \mathrm{min}$, the force also suddenly increases to $83.2 \mathrm{~N}$. $\mathrm{X}$ and Z-axis force change similarly in up milling that shows a decreasing tend between $39.5 \mathrm{~N}$ and $5.4 \mathrm{~N}$. When $\mathrm{v}$ is $1000 \mathrm{~m} / \mathrm{min}$, $X$ force increases to $39 \mathrm{~N}$ and $Z$ force increases to 49.9N. Y-axis force change is similar with $\mathrm{X}$ and $\mathrm{Z}$-axis force. It also has a discontinuity when $\mathrm{v}$ is $1000 \mathrm{~m} / \mathrm{min}$. The stability of $\mathrm{Y}$-axis force is bad.

For WPC of $70 \%$ wood flour content, three forces all show a decreasing tend as the cutting speed increased in Down milling. The force of $\mathrm{Y}$-axis is bigger than $\mathrm{X}$-axis and $\mathrm{X}$ axis is bigger than Z-axis. When $\mathrm{v}$ is $1000 \mathrm{~m} / \mathrm{min}$, Y force increases to $95.1 \mathrm{~N}$ suddenly. Three forces all show a decreasing tend as the cutting speed increased in up milling but the extent is smaller than down milling. $\mathrm{X}$ and Z-axis forces is stable and the change is small. $Y$ force increases suddenly when $\mathrm{v}$ is $1600-1800 \mathrm{~m} / \mathrm{min}$. Especially when $\mathrm{is}$ $1600 \mathrm{~m} / \mathrm{min}$, the force suddenly increases to $88.7 \mathrm{~N}$.

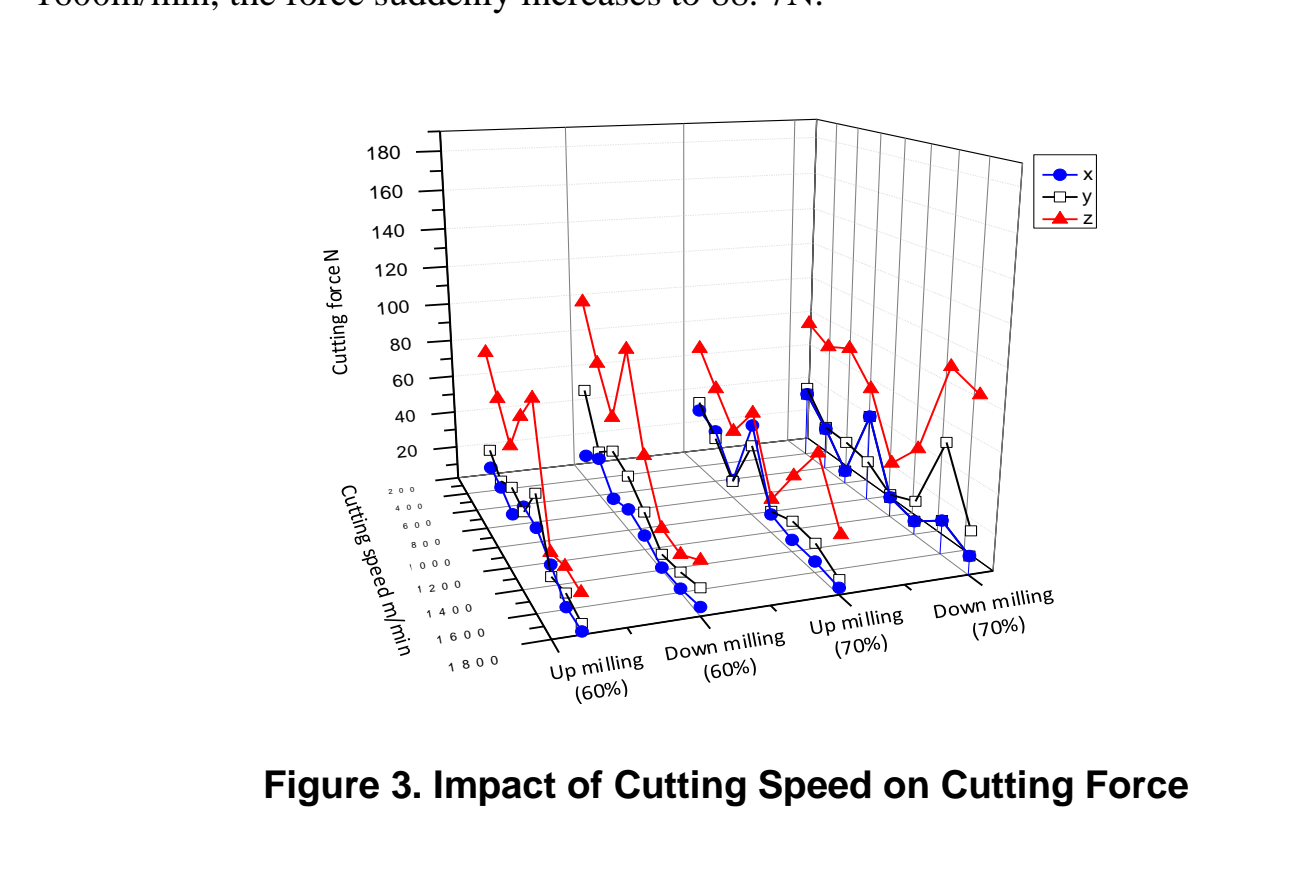

\subsection{Impact of Cutting Width on Cutting Force}

Figure 4 shows the impact of cutting width on cutting force of WPC whose wood flour content is $60 \%$ and $70 \%$ in $\mathrm{XYZ}$ directions during down and up milling. When the content is $60 \%$, three force all increases linearly as the cutting width increases. The cutting force is $\mathrm{Y}>\mathrm{X}>\mathrm{Z}$. $\mathrm{X}$-axis force $(44.8 \mathrm{~N}-63.6 \mathrm{~N})$ waves slightly in up milling. $\mathrm{Z}$ force shows a gradually increasing trend. $\mathrm{Y}$ force $(123.4 \mathrm{~N}-108.4 \mathrm{~N})$ decreases as the cutting width increases but the amount of change is small.

When the content is $70 \%$, three force all increases linearly as the cutting width increases. $\mathrm{X}$ force is stable in up milling which is between $55.2 \mathrm{~N}$ and $68.6 \mathrm{~N}$. When $\mathrm{W}$ is 4-5mm, Z-axis force increases to $99 \mathrm{~N}$ suddenly. $\mathrm{Y}$ force decreases gradually. But when $\mathrm{W}$ is $3-5 \mathrm{~mm}$, it shows an obvious fluctuation. 


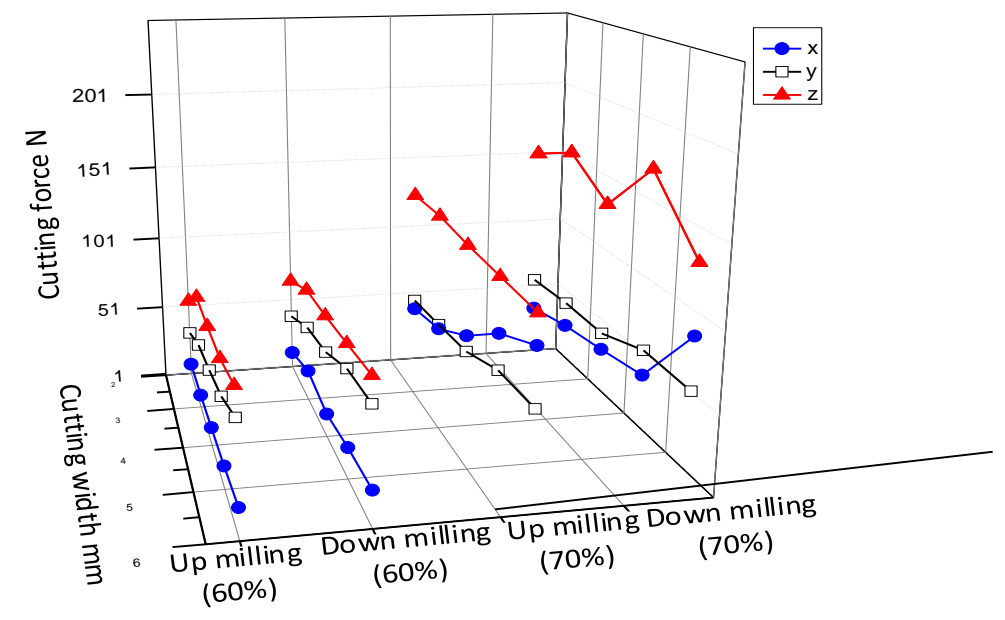

Figure 4. Impact of Cutting Width on Cutting Force,

\section{Cutting Vibration Testing Result}

\subsection{Impact of Feed Speed on Cutting Vibration,}

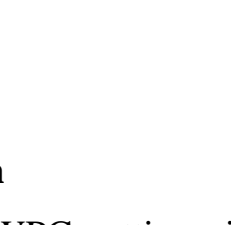

Figure 5 shows the impact of feed speed on WPC cutting vibration of two contents. When the content is $60 \%$ in down nilling, Y-axis Mbration increases gradually from $6.2 \mathrm{~m} / \mathrm{s}^{2}$ to $33.8 \mathrm{~m} / \mathrm{s}^{2}$. X and Z directions also show increasing tend but the fluctuation is very big in each feed speed. The vibrations of all directions increase in up milling. Y-axis vibration is obviously biggen than $X$ and $Z$ axis yibrations.

When the content is $70 \%$, three directions vibrations show an obvious increasing tend when $\mathrm{f}$ is $2-12 \mathrm{~m} / \mathrm{min}$ in down milling. When the feed speed is $14 \mathrm{~m} / \mathrm{min}$, Y-axis vibration decreases obviously, for $20.1 \mathrm{~m} / \mathrm{s}^{2}$ to $14.5 \mathrm{~m} / \mathrm{s}^{2}$. Cutting vibration changes slightly in up milling. The whole vibration is $\mathrm{Y}>\mathrm{X} \geqslant \mathrm{Z}$.

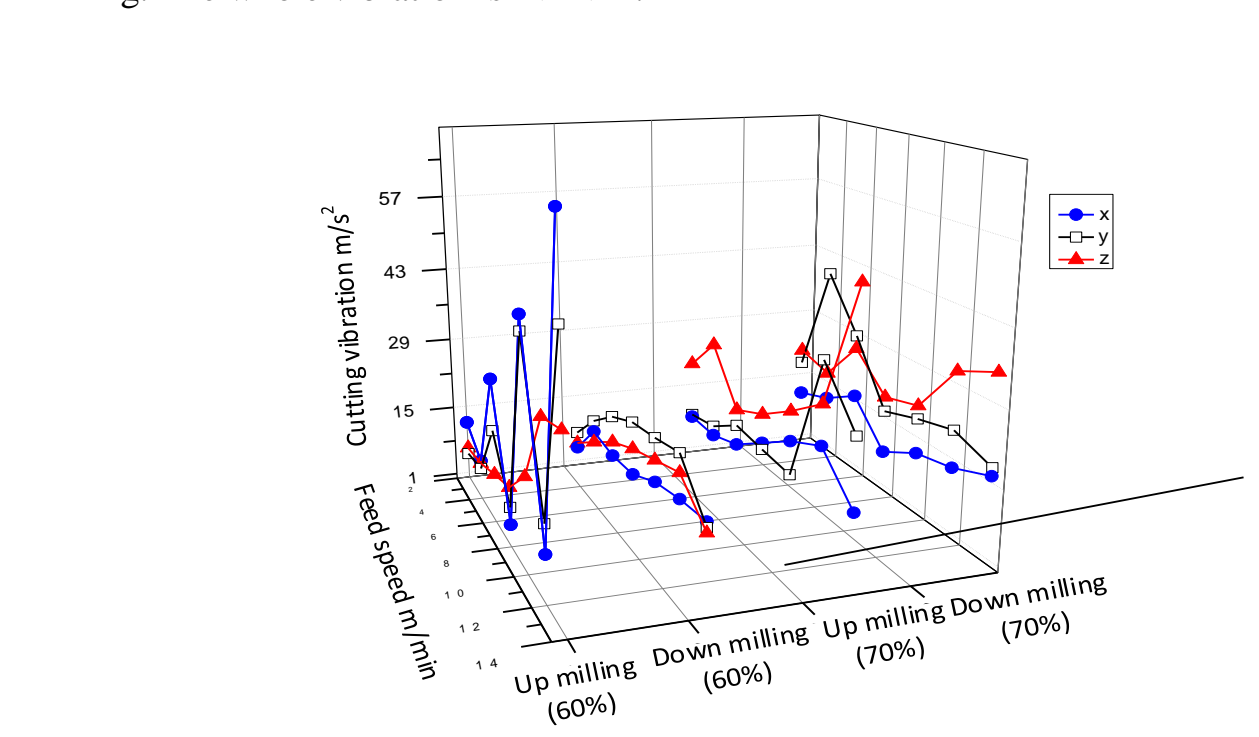

Figure 5. Impact of Feed Speed on Cutting Vibration 


\subsection{Impact of Cutting Speed on Cutting Vibration}

Figure 6 shows the impact of cutting speed on WPC cutting vibration of two contents. When the content is $60 \%$ in down milling, $\mathrm{X}$-axis vibration changes slightly between 4.1 and $19.2 \mathrm{~m} / \mathrm{s}^{2}$. Y-axis vibration changes between 7.8 and $17.8 \mathrm{~m} / \mathrm{s}^{2}$. Z-axis vibration changes between 5.8 and $25.4 \mathrm{~m} / \mathrm{s}^{2}$. X and Z-axis vibrations are stable in up milling. When $\mathrm{v}$ is $400-800 \mathrm{~m} / \mathrm{min}$, the vibration is about $25 \mathrm{~m} / \mathrm{s}^{2}$. When $\mathrm{v}$ is more than $1200 \mathrm{~m} / \mathrm{min}$, the vibration increases to $57.7-67.4 \mathrm{~m} / \mathrm{s}^{2}$.

When the content is $70 \%$, the vibrations of three directions are all around $10 \mathrm{~m} / \mathrm{s}^{2}$ in down milling. When $\mathrm{v}$ is $1600 \mathrm{~m} / \mathrm{min}, \mathrm{Y}$-axis vibration increases to $34.8 \mathrm{~m} / \mathrm{s}^{2}$ suddenly. Cutting vibration shows an increasing trend in up milling. When $\mathrm{v}$ is $1400-1600 \mathrm{~m} / \mathrm{min}, \mathrm{Y}$ axis vibration increases to about $54 \mathrm{~m} / \mathrm{s}^{2}$ suddenly. When cutting speed is $1800 \mathrm{~m} / \mathrm{min}$, the vibration is back to $17.8 \mathrm{~m} / \mathrm{s}^{2}$.

\subsection{Impact of Cutting Width on Cutting Vibration}

\section{Figure 6. Impact of Cutting Speed on Cutting Vibration}

Figure 7 show the mpact of cutting width on WPC cutting vibration of two contents. When the content is $60 \%$ in down milling, the cutting vibration increases first and then decreases. When the cutting width is $4 \mathrm{~mm}, \mathrm{X}$-axis vibration increases to $52.7 \mathrm{~m} / \mathrm{s}^{2}$ suddenl Catting vibration is stable and the change is slight in up milling. The vibration is around $20 \mathrm{~m} / \mathrm{s}^{2}$.

When the content is $70 \%$, three directions all show a slowly increasing trend. Y vibration is obviously bigger than the other two directions in down milling. Cutting vibration is stable in up milling. The sum of three directions vibrations changes slightly, around $33.7-45.7 \mathrm{~m} / \mathrm{s}^{2}$. 


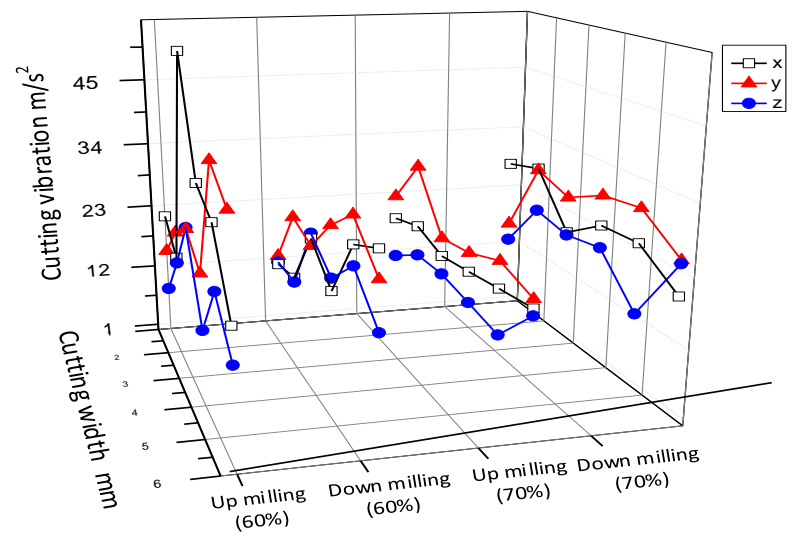

Figure 7. Impact of Cutting Width on Cutting Vibration

\section{Conclusion}

This paper studies the impact of cutting parameters on cutting force and cutting vibration through the milling experiment about PE WPC. We can get the conclusions through the experiment:

1) Cutting force shows a gradually increasing tend as the feed speed increases. In general, cutting force in up milling is biggen than down milling. Cutting force of $70 \%$ content is bigger than $60 \%$ content. Cutting force inop milling is smaller than Down milling as the cutting speed changes Cuting force of $70 \%$ content is higher than $60 \%$ content. Cutting force shows an increasing tend as the cutting width increases. Cutting force in up milling is bigger than cown milling. The force of $70 \%$ content is bigger than $60 \%$ content.

2) Compared with up milling, feed speed has an obvious impact on cutting vibration in down milling. $60 \%$ wood lour content is more easily influenced by feed speed than $70 \%$ content. In the cutting speed experiment, the cutting vibration in up milling is obviously bigger than down milling. The cuting vibration of $70 \%$ content is almost the same with $60 \%$ content in down milling. However, it is opposite in up milling. As the cutting width changes, cutting vibration shows a gradually increasing trend in Down milling, however, it is stable in up milling. Cutting vibration of $60 \%$ wood flour content is bigger than $70 \%$ in down milling. It is opposite in up milling.

\section{Acknowledgiments}

This projectis supported by National Natural Science Foundation of China (Grant No. 51575148), the Natural Science Foundation of Heilongjiang Province of China (E2016048). The authors would like to take this opportunity to express their sincere appreciation.

\section{References}

[1] J. S. Félix, C. Domeño and C. Nerín, "Characterization of wood plastic composites made from landfillderived plastic and sawdust: volatile compounds and olfactometric analysis", Waste Management, vol. 33, no. 3, (2013), pp. 645-655.

[2] J. Dippon, H. K. Ren and F. B. Amara, "Orthogonal Cutting Mechanics of Medium Density Fiberboards", Forest Products Journal, vol. 50, no. 7/8, (2000), pp. 25-30.

[3] S. Engin, Y. Altintas and A. F. Ben, "Mechanics of routing medium density fiberboard", Forest Products Journal, vol. 50, no. 9, (2000), pp. 65-9.

[4] G. Kowaluk, W. Szymansk and B. Palubicki, "Examination of tools of different materials edge geometry for MDF milling”, Holz als Roh- und Werkstoff, vol. 67, no. 2, (2009), pp. 173-6. 
[5] B. D. Jeffrey and T. Gutowski, "An environmental analysis of machining", 2004 ASME International Mechanical Engineering Congress and RD\&D Exposition. Anahelm, California, USA. Proceedings of IMECE, (2004), pp. 1-10.

[6] S. Engin, Y. Altintas and A. F. Ben, "Mechanics of routing medium density fiberboard", Forest Products Journal, vol. 50, no. 9, (2000), pp. 65-9.

[7] H. Liu, "Cutting Forces and Surface Roughness of Wood Plastic Composites in the Process Peripheral Milling”, Nanjing Forestry University, (2012).

[8] Z. Zhang, X. Peng and W. Li, "Influence of Cutting Parameters on Cutting Forces in Wood Sawing", China Wood Industry, no. 3, (2011), pp. 7-10.

[9] Z. Zhang, X. Peng and W. Li, "Influence of Cutting Direction on cutting Forces in Wood", China Wood Industry, no. 6, (2011), pp. 7-9.

[10] Z. Hessainia, A. Belbah and M. A. Yallese, "On the prediction of surface roughness in the hard turning based on cutting parameters and tool vibrations", Measurement, vol. 46, no. 5, (2013), pp. 1671-1681.

[11] F. Eyma, P. J. Méausoone and P. Martin, "Influence of the transitional zone of wood species on cutting of forces in the router cutting process", Holz als Roh- und Werkstoff, vol. 59, no. 6, (2001), pp. 489-490.

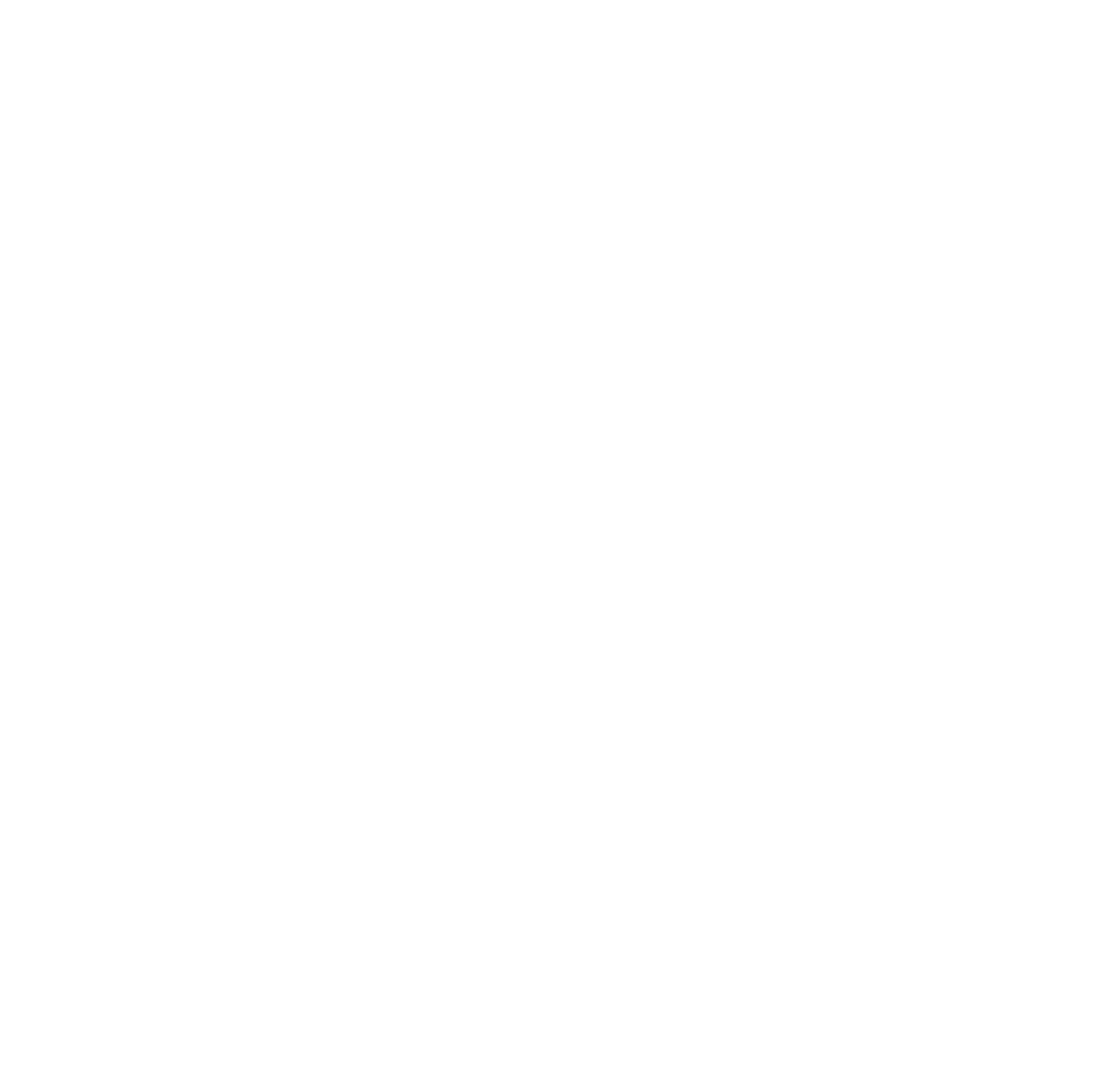

